\title{
Questões teórico-metodológicas da Sociolinguística em interface com o Gerativismo e Funcionalismo linguísticos e o ensino de Língua Portuguesa
}

\author{
Theoretical-methodological questions of Sociolinguistics in \\ interface with linguistic Generativism and linguistic Functionalism \\ and the Portuguese language teaching
}

\author{
Edair Maria Görski \\ Universidade Federal de Santa Catarina, Florianópolis, Santa Catarina, Brasil \\ Marco Antonio Rocha Martins \\ Universidade Federal de Santa Catarina, Florianópolis, Santa Catarina, Brasil
}

\begin{abstract}
Resumo: Apresentamos neste artigo (i) um panorama das abordagens e dos estudos no GT de Sociolinguística da ANPOLL em interfaces entre a Teoria da Variação e Mudança e o Gerativismo e entre a Teoria da Variação e Mudança e o Funcionalismo (especialmente o de vertente norte-americana), bem como (ii) algumas dessas articulações para o ensino de português. No que diz respeito a questões teórico-metodológicas da interface com o gerativismo, mostramos que os estudos apresentam duas fases que não se sobrepõem, mas definem questões de pesquisa e abordagem da variação e mudança sob diferentes perspectivas analíticas: a Sociolinguística Paramétrica e a Competição de Gramáticas. Sobre a interface com o funcionalismo, mostramos que o tratamento teórico-metodológico teve sua fase inicial centrada em condicionadores funcionais de fenômenos variáveis, expandindo-se para uma fase de articulação entre Gramaticalização e Variação em diferentes níveis da gramática. Buscamos mostrar que os estudos em interface não só têm propiciado discussões sobre questões teóricometodológicas no estudo da variação e mudança linguística, mas também têm trazido a público resultados de estudos sobre fenômenos morfossintáticos, sintáticos e discursivos do português que têm ganhado terreno nas discussões sobre ensino de língua.
\end{abstract}

Palavras-chave: Interfaces; Sociolinguística Paramétrica; Competição de Gramáticas; Sociofuncionalismo; Ensino

\begin{abstract}
In this article we present (i) an overview of the approaches and studies in ANPOLL's Sociolinguistics working group in interfaces between the Theory of Variation and Change and Gerativism and between the Theory of Variation and Change and Functionalism (especially the North American one), as well as (ii) some of these articulations for teaching Portuguese.
\end{abstract}

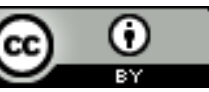


Regarding the theoretical-methodological issues of the interface with gerativism, we show that the studies present two phases that do not overlap, but define questions of research and approach to variation and change from different analytical perspectives: Parametric Sociolinguistics and Grammar Competition. On the interface with functionalism, we showed that the theoretical-methodological treatment had its initial phase centered on functional conditioners of variable phenomena, expanding to a phase of articulation between Grammaticalization and Variation at different levels of grammar. We sought to show that interface studies have not only provided discussions on theoretical-methodological issues in the study of variation and linguistic change, but have also brought to the public results of studies on morphosyntactic, syntactic and discursive Portuguese phenomena that have gained ground in language teaching discussions.

Keywords: Interfaces; Parametric Sociolinguistics; Grammar Competition; Sociofunctionalism; Teaching

\section{Introdução}

O objetivo deste artigo se desdobra em: (i) explorar motivações, conquistas, potencialidades e desafios da articulação teórico-metodológica entre a Teoria da Variação e Mudança linguística ${ }^{1}$ e a Gramática Gerativa e entre a Teoria da Variação e Mudança e a abordagem funcionalista, notadamente a de vertente norte-americana, considerando pesquisas e publicações realizadas por membros do Grupo de Trabalho Sociolinguística e Dialetologia da Associação Nacional de Pós-Graduação em Letras e Linguística (ANPOLL), ao longo desses 35 anos de atividades do GT; e (ii) considerar contribuições para o ensino de português. As interfaces contemplam fenômenos de nível morfossintático, sintático e discursivo (este último restrito à perspectiva sociofuncionalista).

O artigo está organizado em três seções. Na primeira delas, fazemos uma breve retrospectiva dos estudos em articulação teórica no GT. Na seção 2 apresentamos algumas considerações sobre questões teóricas e metodológicas dos estudos em interface com o gerativismo e o funcionalismo e um breve quadro de resultados de pesquisa alcançados. Em 3, buscamos resumidamente apresentar algumas contribuições dos estudos em interface para o ensino de português.

\footnotetext{
${ }^{1}$ Neste texto, utilizamos alternadamente os termos Teoria da Variação e Mudança, Sociolinguística Variacionista e Sociolinguística, considerando-se que o enfoque é o de tradição laboviana.
}

Revista da Anpoll, Florianópolis, v. 52, n. esp., p. 173-197, jan.-dez., 2021 | 174 


\section{Breve retrospectiva}

Vandresen (2003) descreve minuciosamente a trajetória do GT de Sociolinguística da ANPOLL desde 1985, data de sua criação que coincide com a data de criação da Associação, até 2001, e Savedra (2010) dá continuidade a essa descrição até 2010. A partir de então, há informações disponíveis no site do GT, especialmente nos planos de trabalho e nos relatórios dos biênios. ${ }^{2}$ Valemo-nos, inicialmente, desses registros para sistematizar indicativos de estudos em interface da Sociolinguística com diferentes perspectivas teóricas ao longo da trajetória do GT, com foco em abordagens formalista e funcionalista e possíveis aplicações ao ensino de língua.

Desde a sua criação, o GT de Sociolinguística esteve voltado à diversidade linguística observada sob diferentes ângulos: variação e mudança, multilinguismo, bilinguismo e línguas em contato, dialetologia, sociolinguística interacional. Já no I Encontro Regional (1986), realizado no Rio de Janeiro, foi definido em ata que "o GT é algo independente de teoria ou corrente, naturalmente eclético, sob o risco de ser o GT confundido com linha de pesquisa".

No II Encontro Nacional da ANPOLL (1987), a programação do GT incluía uma sessão sobre "Projetos de variação e mudança na área da sintaxe, na perspectiva paramétrica", coordenada por Fernando Tarallo. O V Encontro (1990), realizado em Recife, destinou um espaço para uma mesa-redonda sobre "Sociolinguística paramétrica". Essa temática também esteve presente na fala de Jânia Ramos na mesa sobre "Os estudos da variação no Brasil: situação atual”, no VII Encontro Nacional (1992), em Porto Alegre. O VIII Encontro (1994), realizado em Caxambu/GO, contou com a mesa inter-GTs "Sintaxe histórica do português: teorias, métodos e dados", coordenada por Rosa Virgínia Mattos e Silva, articulando os GTs de Sociolinguística e Teoria da Gramática. A perspectiva teórica que ganhava relevo e especial atenção nos estudos em interface com a Teoria da Variação e Mudança Linguística no GT nesse período era a gerativista na empreitada de um "projeto herético" (TARALLO, 1986, 1987, 1988; TARALLO; KATO, 1986 [2007]), capitaneada por Tarallo e colaboradores, tendo São Paulo como centro irradiador.

\footnotetext{
${ }^{2}$ Disponível em: http://anpoll.org.br/gt/sociolinguistica/. Acesso em: 18 de novembro de 2020.
} 
Paralelamente, a abordagem funcionalista associada à variação ganhava impulso no Brasil com o projeto Mecanismos Funcionais do Uso Linguístico, coordenado por Sebastião Votre, no âmbito do Programa de estudos sobre o uso da língua - PEUL/UFRJ, na década de 1980, seguindo uma orientação funcionalista norte-americana com base em Sandra Thompson, Paul Hopper, Talmy Givón, entre outros (cf. GÖRSKI; OLIVEIRA; PIMPÃO, 2020). O final da década de 1980 e o início da seguinte marcaram um vigoroso debate sobre funcionalismo versus formalismo, que teve forte impacto no meio acadêmico brasileiro, com os seguintes artigos publicados na revista D.E.L.T.A.: "Mecanismos funcionais do uso da língua" (VOTRE; NARO, 1989); “Teoria gramatical e mecanismos funcionais do uso da língua" (NASCIMENTO, 1990); "Forma e função na linguística" (DILLINGER, 1991); e "Mecanismos funcionais do uso da língua: função e forma" (NARO; VOTRE, 1992). ${ }^{3}$

Embora as discussões teóricas sobre funcionalismo e formalismo fossem significativas na academia em diferentes IES no Brasil desde a década de 1980, no âmbito do GT, ao que parece, somente na década de 1990 as interfaces entre diferentes modelos teóricos e a Sociolinguística começam a ganhar visibilidade. Em 1995, sob a então coordenação de Sílvia Brandão, o GT promoveu na UFRJ o Simpósio "Modelos de análise em debate" (BRANDÃO, 1995) que abre um espaço de discussão sobre a temática das interfaces. No XI Encontro Nacional da ANPOLL (1996), realizado em João Pessoa, a mesa inter-GTs coordenada por Mattos e Silva integrava discussões sobre mudança linguística nas perspectivas gerativista (Charlotte Galves), variacionista/laboviana (Anthony Naro) e funcionalista (Sebastião Votre). Nesse evento, foi apresentada a coletânea Variação e discurso (1996), organizada por Alzira Tavares de Macedo, Cláudia Roncarati e Maria Cecília Mollica, associadas do GT, que reúne trabalhos produzidos no âmbito do PEUL.

Por ocasião do XIV Encontro Nacional da ANPOLL (2000), realizado em Niterói/RJ, o GT de Sociolinguística dedicou uma de suas sessões, coordenada por Maria Cecília Mollica e Cláudia Roncarati, para discutir

os avanços teórico-metodológicos alcançados pelos estudos variacionistas, particularmente na interface com outros quadros teóricos, entre os quais, os

\footnotetext{
${ }^{3}$ Na programação Abralin ao vivo (2020), Sebastião Votre resgata e atualiza algumas discussões pertinentes à interface entre a Sociolinguística e o Funcionalismo linguístico na live "Mecanismos funcionais: 30 anos depois". Disponível em: https://aovivo.abralin.org/lives/
}

Revista da Anpoll, Florianópolis, v. 52, n. esp., p. 173-197, jan.-dez., 2021 | 176 
voltados para uma perspectiva funcional-discursiva, para aquisição e a teoria gerativa. Foi ainda apresentada uma vertente aplicada, que constitui preocupação do GT desde as gestões de Suzana Cardoso e de Sílvia Brandão e que se encontra atualmente em expansão. A forma de se tornar disponíveis ao professor os resultados da pesquisa sociolinguística e de se operacionalizar essa passagem de conceitos para a escola foi um dos focos da discussão. (VANDRESEN, 2003, p. 23-24; grifos acrescidos)

Trata-se de um momento importante na trajetória do GT, quando explicitamente os avanços das interfaces teóricas começam a ser considerados, bem como ganham mais visibilidade as preocupações com o ensino. Mollica e Roncarati publicam, em 2001, o artigo "Questões teórico-descritivas em sociolinguística aplicada e uma proposta de agenda". Nas palavras das autoras:

Constata-se, no conjunto dos estudos, uma pluralidade teórico-metodológica nitidamente presente, demonstrando que: (a) as pesquisas sobre o uso da língua não podem restringir-se a dogmatismos teóricos; (b) a mudança lingüística tem de ser estudada sob diferentes enfoques, se se deseja uma compreensão mais aprofundada do dinamismo inerente às línguas. [...] (MOLLICA; RONCARATI, 2001, p. 51)

Em relação a uma agenda de trabalho, as autoras pontuam:

(a) exame da tensão entre fatores sociais e funcionais; (b) reflexão sobre a natureza da variação; [...] (d) inter-relações entre variacionismo, geografia dialetal, funcionalismo e gerativismo. (MOLLICA; RONCARATI, 2001, p. 51; grifos acrescidos)

Em 2003, o GT lança Português brasileiro: contato linguístico, heterogeneidade e história, organizado por Jussara Abraçado e Cláudia Roncarati. Embora a obra tenha priorizado as três vertentes que compunham o GT até então - dialetologia, variação e mudança e multilinguismo -, as diferentes perspectivas teóricas foram explicitamente contempladas no capítulo "O formal e o funcional na teoria variacionista", escrito por Roberto Camacho, bem como em outros capítulos cuja análise dos fenômenos variáveis se ancora numa ou noutra dessas abordagens.

Foi na reunião nacional do GT no XXIII ENANPOLL (2008) em Goiânia-GO, que o eixo "Interfaces teóricas" aparece assim referido com o objetivo de suscitar discussões teóricas e metodológicas no âmbito da análise de dados em sociolinguística, apesar de estar já no rol dos interesses do grupo, explicitamente desde 1995. Além da 
definição do eixo "Interfaces teóricas”, são listadas as orientações do GT que contemplam "princípios universais", "novas metodologias", "adequação de modelos para a área"4.

Em 2008, sai Português Brasileiro II: contato linguístico, heterogeneidade e história, também organizado por Abraçado e Roncarati, e na parte destinada a heterogeneidade, as descrições e explicações de fenômenos variáveis continuam se embasando em pressupostos formais ou funcionais.

De acordo com o relatório de Mônica Savedra e Jürgen Heye (biênio 2008-2010), a discussão sobre interfaces teóricas e novas metodologias era uma das metas propostas pelo GT, meta que se concretiza como um dos eixos temáticos na gestão de Marco Antonio Martins e Maria Alice Tavares (2010-2012) com o nome de "Interfaces teóricometodológicas". No biênio seguinte, esse eixo se consolida sob a responsabilidade de Rosane Berlinck e Marco Antonio Martins. Em 2017, o nome do eixo é alterado para “Teorias e Métodos para o Estudo da Variação e Mudança Linguísticas" e sua coordenação passou a contar também com a participação de Jussara Abraçado.

Na sequência de publicações do GT, em 2015, é lançada a obra Mapeamento sociolinguístico do português brasileiro, organizada por Marco Antonio Martins e Jussara Abraçado, que contempla, na parte II - A Sociolinguística em interface -, um capítulo sobre "Variação sintática e gerativismo" (MARTINS; COELHO; CAVALCANTE, 2015) e outro sobre "Variação e sociofuncionalismo" (TAVARES; GÖRSKI, 2015) ${ }^{5}$, que aborda, entre outros aspectos, a relação entre variação e gramaticalização, temática também tratada numa perspectiva mais histórica no capítulo "Variação e gramaticalização" (RAMOS; MENON, 2015), além do capítulo "Variação e cognição (ABRAÇADO, 2015).

No relatório do biênio 2016-2018, Cláudia Regina Brescancini e Valéria Neto de Oliveira Monaretto assim descrevem a ementa do eixo:

Estando bem estabelecida a relevância de interfaces teórico-metodológicas nos
estudos sociolinguísticos, este eixo temático constitui um espaço para que se
possa discutir teoria (ou teorias) e métodos para o estudo da variação e
mudança linguística. Depois de um vasto e significativo esforço de descrição
e análise de diferentes fenômenos da realidade linguística brasileira, necessário
se faz enveredarmos pelos pressupostos teórico-metodológicos que envolvem

${ }^{4}$ http://anpoll.org.br/gt/sociolinguistica

5 Um aprofundamento das discussões que se iniciaram no eixo temático do GT sobre a interface entre Sociolinguística e Funcionalismo de vertente norte-americana pode ser conferido em Görski e Tavares (2017).

Revista da Anpoll, Florianópolis, v. 52, n. esp., p. 173-197, jan.-dez., 2021 | 178 
a questão da variação e mudança em busca de sistematizar importantes contribuições evidenciadas nos muitos anos de estudo no Brasil e responder questionamentos surgidos desse robusto conjunto de pesquisas.

Desde o momento em que se instituiu o eixo de interfaces (cujas abordagens vêm se expandindo para além da dicotomia funcionalismo/formalismo), os encontros do GT têm reservado espaço para apresentação e discussão de trabalhos de seus membros, aprofundando e ampliando as articulações teórico-metodológicas.

No "I Fórum Internacional em Sociolinguística: descrição, teoria, metodologia e ensino" e "II Encontro Internacional do GT de Sociolinguística", realizados em novembro de 2019 na UFRJ, Martins, Berlinck e Abraçado enfatizam a relevância dos estudos desenvolvidos no âmbito do eixo Teorias e Métodos para o Estudo da Variação e Mudança Linguísticas e o reafirmam como um "espaço para que se possa discutir teoria (ou teorias) e métodos para o estudo da variação e mudança linguística no âmbito do GT de Sociolinguística.”. A proposta dos autores é a de que os estudos realizados no eixo são de extrema importância para a busca de sistematizações de teóricas tendo em vista os muitos anos de estudos de descrição e análise de dados linguísticos do português no Brasil.

\section{A Sociolinguística em interfaces}

Considerando a tradição no GT em realizar estudos em interfaces entre a Sociolinguística Variacionista e perspectivas formal e funcional para o estudo de processos em variação e mudança no português, apresentamos aqui uma breve contextualização dessas articulações teórico-metodológicas assim como algumas referências de estudos publicados e um breve quadro de fenômenos abordados.

\subsection{A interface Sociolinguística e Gerativismo}

Como muito bem afirma Duarte (2016), se, nas pesquisas clássicas de William Labov sobre as variedades do inglês americano, as variáveis estudadas estiveram fortemente centradas em fenômenos fonético-fonológicos, no Brasil, os estudos pioneiros foram sobre fenômenos morfossintáticos, e comprovam isso, por exemplo, as dissertações de

Revista da Anpoll, Florianópolis, v. 52, n. esp., p. 173-197, jan.-dez., 2021 | 179 
mestrado de Maria Cecília Mollica (1977) sobre as estratégias de relativização, de Nelize Omena (1978) sobre a representação do acusativo anafórico, e de Maria Luiza Braga (1978) sobre a concordância nominal. Esse quadro abriu espaço para um programa de estudos em interface entre a Teoria da Variação e Mudança linguística (TVM) e a Teoria da Gramática Gerativa (GG) sobre fenômenos morfossintáticos do português no Brasil, numa tentativa de conciliar pressupostos da teoria da mudança da Sociolinguística Variacionista e categorias de análise linguística do Gerativismo.

Buscando delinear essa articulação entre a TVM e a GG no âmbito do GT, entendemos que os estudos em sintaxe diacrônica desenvolvidos no Brasil se apresentam em duas fases, que não seguem propriamente uma sucessão temporal, nem se sobrepõem no sentido de que, como ondas, criam um contínuo atemporal de realinhamento teórico. A primeira dessas fases, a Sociolinguística Paramétrica, ou variação paramétrica (RAMOS, 1999), tem como precursores os trabalhos desenvolvidos e orientados por Fernando Tarallo (com um primeiro desenho no trabalho de Tarallo $(1986,1987,1988)$ ) e Mary Kato, que culminam com a publicação do texto-manifesto, hoje clássico, "harmonia transistêmica: do inter ao intra linguístico" (TARALLO; KATO, 1989 [2007]. A segunda fase, a Competição de Gramáticas, foi fortemente influenciada pelos trabalhos realizados de Charlotte Galves acerca da competição entre gramáticas do português, tomando por base o modelo de Anthony Kroch (1989, 2001).

A primeira fase dessa articulação teórica, a Sociolinguística Paramétrica, formou um grupo de pesquisadores e solidificou resultados de pesquisas sobre mudanças morfossintáticas do português brasileiro. Constitui uma forte linha de pesquisa, com estudos diacrônicos em busca de explicações de processos de mudanças diagnosticadas no português brasileiro em comparação ao português europeu e tem em Tarallo e Kato (1989 [2007]) a proposta basilar centrada no pressuposto de que variação paramétrica interlinguística advogada pela Teoria Gerativa, centrada na diferenciação entre os parâmetros que marcam diferentes línguas, pode ser observada na variação intralinguística seguindo o postulado central da Sociolinguística sobre heterogeneidade sistemática.

As sementes plantadas pelo "projeto herético" da Sociolinguística Paramétrica (KATO, 1999) renderam certamente muitos frutos, pois esse projeto orientou/tem orientado a formação de um grupo de pesquisadores que levou/tem levado à frente um

Revista da Anpoll, Florianópolis, v. 52, n. esp., p. 173-197, jan.-dez., 2021 | 180 
plano de pesquisa com resultados sólidos sobre a sintaxe diacrônica do português brasileiro, como se pode ver, por exemplo, nos artigos publicados em Roberts e Kato (1993) e Galves, Roberts, Kato (2019). Inúmeros trabalhos de membros do GT mostram que as predições de Tarallo (1993, p. 99) de que a PB "emergiu ao final do século XIX" estavam corretas, no sentido que de que "o cidadão brasileiro já estava de posse, ao final [desse século], de sua própria língua/gramática". Esse diagnóstico se fundamenta na observação empírica da escrita de brasileiros - tendo em vista a análise de cartas pessoais, diários e peças de teatro -, e num quadro de mudanças de fenômenos morfossintáticos amplamente descrito.

As dissertações de mestrado, as teses de doutorado e os inúmeros artigos de membros do GT ao longo dos anos têm apresentado um diagnóstico da gramática do PB como ilustra o breve quadro descrito a seguir. ${ }^{6}$

(1) Uma reestruturação do sistema pronominal, com a entrada das formas inovadoras você e a gente para a expressão da segunda pessoa do singular e da primeira do plural no paradigma pronominal nas funções nominativa, acusativa, dativa e reflexiva, desde os trabalhos pioneiros de Duarte (1984 e 1986) sobre a variação na expressão do acusativo de terceira pessoa e o mapeamento mais atual de Duarte e Ramos (2015). Ainda sobre essa reestruturação, os estudos de Duarte (1993, 1995, 2012, entre muitos outros), Soares da Silva (2006; 2011), Marins (2009, 2013) e Duarte e Soares da Silva (2016) têm mostrado a expressiva mudança em direção à retenção do sujeito pronominal em direção a perdas gramaticais de propriedades de uma língua pro-drop consistente (DUARTE, 2018); assim como Berlinck et al. (2016), seguindo os muitos estudos de Cyrino (sobretudo CYRINO $(1994 ;$ 1997)), mostram o apagamento do objeto direto anafórico.

(2) Uma significativa mudança no sistema e nos padrões de posição e colocação dos clíticos pronominais, com a perda do acusativo de terceira pessoa $o / a$, o espraiamento do dativo the para a segunda pessoa e a entrada de formas plenas nas funções acusativa, dativa e oblíqua e significativa mudança nos padrões de posição e colocação dos clíticos pronominais em direção à próclise em sentenças raízes finitas com um verbo e em direção à próclise ao verbo temático em construções complexas com dois verbos (CAVALCANTE, DUARTE, PAGOTTO, 2011).

\footnotetext{
${ }^{6}$ Muito naturalmente, os estudos realizados em sintaxe diacrônica seguindo os pressupostos da Sociolinguística Paramétrica vão além dos aqui citados. Nosso recorte tem por parâmetro os trabalhos de membros do GT de Sociolinguística da ANPOLL.
}

Revista da Anpoll, Florianópolis, v. 52, n. esp., p. 173-197, jan.-dez., 2021 | 181 
(3) Uma reestruturação nos padrões sentenciais básicos em direção à anteposição do sujeito gramatical, estando a posposição restrita a contextos de inacusatividade, como mostram os trabalhos de Berlinck $(1995,2000)^{7}$, Coelho $(2000 ; 2006)$ e Berlinck e Coelho (2018).

A segunda fase nos estudos em interface entre a TVM e a GG, que não se sobrepõe à anterior como afirmamos, encontra lugar nos trabalhos que assumem o modelo de Competição de Gramáticas. Essa proposta busca observar a alteração na frequência de uso de fenômenos sintáticos sob a interpretação de uma mudança gramatical/estrutural em si e por si que estabelece a competição entre formas geradas por diferentes gramáticas do português no curso do tempo e não como uma variação intralinguística na gramática do português brasileiro no curso dos séculos, como mostra Martins (2013) numa discussão sobre o problema empírico de implementação. A alteração observada nos dados linguísticos no curso do tempo pode ser o reflexo de uma mudança gramatical no sentido de que quando um parâmetro na gramática for alterado, a mudança no curso do tempo nos textos empíricos pode se refletir em diferentes fenômenos superficiais. São precursores dessa articulação teórica no âmbito do GT de Sociolinguística as teses de doutorado de Silvia Cavalcante (2006 e trabalhos posteriores 2011; 2018) sobre o uso do pronome $S E$ passivo e indefinido na história do português e de Marco Martins (2009 e trabalhos posteriores 2012, 2018) sobre a sintaxe de posição e os padrões de colocação dos pronomes clíticos em direção à próclise na escrita brasileira dos séculos XIX e XX. Ilustram trabalhos nessa fase, ainda, os projetos e publicações de Cavalcante e Martins sobre os padrões de ordenação do sujeito e sobre o sujeito nulo na escrita brasileira numa perspectiva histórica, como mostram Martins, Cavalcante e Coelho (2020).

Uma grande diferença existente entre as duas fases na articulação da TVM e da GG recai na questão da implementação. Para a Sociolinguística Paramétrica, a mudança pode ser capturada em andamento, seguindo o que propõe Weinreich, Labov e Herzog (2006 [1968]), para os quais o problema da implementação, por exemplo, está relacionado a todo o percurso de mudança, da origem a sua propagação e completude, estando em foco de análise aumento gradativo da frequência da nova variante na comunidade de fala até atingir os $100 \%$ e a forma variante desaparecer. Na teoria de Princípios e Parâmetros

\footnotetext{
${ }^{7}$ É importante destacar aqui que os trabalhos iniciais de Berlinck $(1988,1989)$ sobre os padrões de ordenação do sujeito no português foram realizados sob viés formal e funcional.
}

Revista da Anpoll, Florianópolis, v. 52, n. esp., p. 173-197, jan.-dez., 2021 | 182 
da teoria gerativa, e consequentemente para uma teoria de mudança linguística centrada nos pressupostos dessa teoria como o modelo de competição de gramáticas, a implementação da mudança ocorre justamente no início do processo: quando a nova forma começa a aparecer na comunidade já ocorreu a mudança paramétrica.

Assim, a maneira como os dois quadros teóricos são conjugados difere daquela entendida pela Sociolinguística Paramétrica praticada no Brasil, pois o ponto de partida para o modelo de competição de gramáticas é que a variação não esteja na gramática: a variação observada nos dados é fruto de duas (ou mais) gramáticas distintas, ou seja, duas (ou mais) marcações paramétricas distintas. Nesse sentido a variação está no Sistema, mas não na Gramática (cf. MARTINS; COELHO; CAVALCANTE, 2015). Assim, o comportamento estatístico dos dados no período de mudança, a famosa curva em "S", é interpretado de modo distinto entre os dois quadros. A curva em " $\mathrm{S}$ " é para a Sociolinguística Paramétrica a comprovação empírica de que a mudança sintática é gradual. Para o modelo de Competição de Gramáticas, a curva em "S" assinala a competição entre duas (ou mais) gramáticas distintas.

\subsection{A interface Sociolinguística e Funcionalismo}

A articulação aqui considerada conjuga o aporte teórico-metodológico da Sociolinguística Variacionista com os princípios do Funcionalismo linguístico de vertente norte-americana, perspectiva funcional que tem se mostrado mais presente em trabalhos de membros do GT. O principal ponto de convergência dessa interface é a variação linguística, que tem recebido basicamente dois tipos de tratamento analítico: (i) são considerados condicionadores de natureza funcional tanto para fenômenos variáveis de nível morfossintático como para fenômenos de nível textual/discursivo, no sentido de que a forma é a variável dependente e a função (entendida basicamente como significação semântico-pragmática contextualmente apreendida) é a variável independente (cf. NARO; VOTRE, 1992); (ii) o fenômeno variável é inicialmente delimitado dentro de um domínio funcional, cujas formas são resultantes de mudança(s) via gramaticalização, conforme o princípio da estratificação (HOPPER, 1991) - abordagem apontada por Naro e Braga (2000) e defendida com argumentos robustos no campo da sociolinguística por Poplack (2011) e Torres Cacoullos (2011), entre outros -, sendo a variação explicada por 
condicionadores funcionais que contemplam também, em alguma medida, as trajetórias de mudança dos itens envolvidos. Nessa segunda perspectiva, a multifuncionalidade dos itens também é considerada, pois o recorte da variável se dá em um domínio funcional, ou seja, no campo da coexistência de duas ou mais formas para uma função/significação.

O primeiro tipo de tratamento teórico-metodológico caracterizou os trabalhos iniciais desenvolvidos nessa interface a partir da década de 1980, tendo o PEUL/UFRJ como centro irradiador desse tipo de prática analítica. Ilustram essa fase as teses de Vera Lúcia Paredes da Silva (1988) sobre a variação do sujeito e de Maria da Conceição Paiva (1991) sobre ordenação de orações, entre outros trabalhos, cuja abordagem se estende a seus orientandos e tem inspirado outros pesquisadores interessados nesses objetos de pesquisa. Destaca-se também o estudo de Giselle Silva e Alzira Macedo (1966) sobre análise sociolinguística de marcadores discursivos, que abriu caminho para o tratamento de variáveis de natureza discursiva e tem sido usado como referência importante nesse campo.

O segundo tipo tem estado presente em pesquisas a partir da década de 2000, tendo recebido uma sistematização robusta nos trabalhos de: Maria Alice Tavares (1999; 2003) - que articula gramaticalização e variação no estudo de conectores; Raquel Freitag (2007) - que aproxima gramaticalização a uma abordagem evolutiva da língua na análise de categorias verbais; Carla Valle (2014) - que introduz na interface gramaticalização/variação aspectos estilísticos e identitários no estudo de marcadores discursivos; Marcela Bragança (2017) - que propõe uma articulação entre os campos variacionista, funcionalista e dialógico, a partir de reflexões sobre a expressão do futuro do presente; entre outros trabalhos.

Inúmeras teses, dissertações e outras publicações têm sido produzidas nessa interface por membros do GT (direta ou indiretamente, em parcerias e/ou orientações), seja na linha de (i), que se mantém bastante robusta, seja na linha de (ii), com o aporte da gramaticalização, ou seja ainda mesclando essas linhas. Podemos mencionar, por exemplo, os estudos de Odete Menon (1995), Ana Zilles (2007) e Célia Lopes (2008) dentre outros publicados por essas autoras - sobre a gramaticalização dos pronomes você e/ou a gente (e variação com tu e nós), que são referências importantes para aqueles que se voltam ao paradigma pronominal; as teses de Cláudia Rost-Snichelotto (2009) e Tatiana Pimpão (2012), que versam, respectivamente, sobre variação de marcadores 
discursivos interacionais e modo subjuntivo/indicativo, com aporte teórico sociofuncionalista; a tese de Valter Dias (2017), que trata da indeterminação do sujeito. Há também projetos de pesquisa já realizados e em andamento que focalizam explicitamente essa interface, como o de Marcia dos Santos Machado Vieira, sobre predicados complexos e o de Valéria Sousa, sobre estudos de fenômenos linguísticos na perspectiva sociofuncionalista, com várias publicações relacionadas, próprias e/ou em parcerias. Em uma rápida busca por publicações atuais de membros do GT que assumem uma interface sociofuncionalista, encontramos os artigos de Lilian Yacovenco e Caroliny Massariol (2020) sobre variação do sujeito pronominal e de Valéria Sousa e Warley Rocha (2020) sobre a alternância entre você e $c \hat{e}^{8}$

Para além da abordagem sociofuncionalista nos termos acima descritos, mas afinados com ela, no âmbito do GT, verificam-se outros movimentos de articulação teórico-metodológica. Rosane Berlinck e Vera Lúcia Paredes da Silva coordenam projetos integrados que envolvem variação/mudança e análise de gêneros textuais. Como pontuam Langa-Lacerda e Görski (a sair), ao discutirem o potencial analítico dos gêneros do discurso para os estudos variacionistas, a questão dos gêneros tem estado presente em várias pesquisas variacionistas, sendo operacionalizado como uma variável independente aplicada tanto a entrevistas como a amostras escritas, ou usado como critério organizador de amostras, ou ainda acionado para discussões teórico-metodológicas (cf. TESCH, 2011; VIEIRA, 2014; FREITAG, 2014; BERLINCK; BIAZOLLI; BALSALOBRE; 2014; BRAGANÇA, 2017; entre outros).

Com a tendência de aproximação do funcionalismo à linguística cognitiva, especialmente com base em pressupostos de modelos baseados no uso com foco no tratamento de construções, tem se verificado também um movimento de articulação entre gramática de construções e variação/mudança (cf. PAIVA; GOMES, 2016; WIEDEMER; MACHADO VIEIRA, 2018; MACHADO VIEIRA; WIEDEMER, 2019).

\footnotetext{
${ }^{8}$ Existem muitos outros trabalhos desenvolvidos na perspectiva sociofuncionalista que deixaram de ser mencionados aqui por uma limitação de espaço. Vale registrar que publicações com essa abordagem extrapolam os limites do GT de Sociolinguística, evidenciando a produtividade dessa interface, seja na operacionalização de hipóteses, seja na explanação teórica dos resultados. Cumpre salientar que diferentes configurações da interface vão sendo refinadas à medida que as pesquisas nesse campo avançam.
}

Revista da Anpoll, Florianópolis, v. 52, n. esp., p. 173-197, jan.-dez., 2021 | 185 


\section{Contribuições para o ensino de português}

Que contribuições os estudos em interface entre a TVM e o Gerativismo e o Funcionalismo - ou Sociofuncionalismo - desenvolvidos no âmbito do GT de Sociolinguística podem oferecer ao ensino de português?

Em termos mais gerais, o estudo de processos de variação e mudança linguísticas associados a teorias linguísticas, que, como procuramos mostrar, encontrou um terreno fértil no Brasil, tem tornado a bagagem de conhecimentos do professor mais sólida, no sentido de uma compreensão mais ampla do funcionamento da língua em uso - pensados aqui em termos de forma e função - e isso naturalmente se reflete na prática de ensino e aprendizagem.

Em relação à interface Sociolinguística e Gerativismo, mais especificamente (mas não restrito a - tendo em vista os muitos trabalhos em diferentes perspectivas teóricas sobre o assunto -), as descrições e análises de processos de mudança têm disponibilizado um robusto material para repensar o ensino de português considerando um sistema pronominal reestruturado para as três pessoas do singular e plural nas diferentes funções: nominativa (primeira pessoa: eu/nós a gente; segunda pessoa: tu você/vocês; terceira pessoa: ele(a)/eles(as)), acusativa (me/nos $\sim$ nós $\sim$ a gente; te $\sim$ lhe $\sim$ ola $\sim s e \sim$ tu/você; $o / a(s) \sim \operatorname{se} \sim \operatorname{ele}(a) / e l e s(a s))$, dativa $(m e / n o s \sim$ nós $\sim$ a gente; te $\sim$ lhe $\sim$ tu/você; lhe $\sim$ ele $(a)$ /hes $\sim$ eles (as) ) e oblíqua (mim $\sim$ comigo $\sim$ eu/nós $\sim$ conosco $\sim$ a gente; ti $\sim$ contigo $\sim$ você $\sim$ você mesmo/vocês vocês mesmos; ele $(a) \sim \operatorname{ele}($ a $)$ mesmo $($ a) /eles $($ as $) \sim \operatorname{eles}($ as $)$ mesmos(as)). Esse quadro pode ser encontrado em Duarte (2013) e Martins, Vieira e Tavares (2013) além de outras publicações sobre a temática. Além dessas funções, como afirma Duarte (2013, p. 122), os estudos têm mostrado que o pronome se indefinido "está restrito à fala de indivíduos pertencentes a faixas etárias mais altas, mas, mesmo entre esses, se indefinido perde para o uso de você e a gente, além de um sujeito nulo com o verbo na terceira pessoa do singular (não usa mais chapéu) para referência indeterminada".

Ainda sobre essa reestruturação no sistema pronominal, ou a essa diretamente vinculada, estudos têm mostrado a aplicação de resultados a uma discussão sobre o ensino da categoria sujeito gramatical considerando as mudanças em direção ao preenchimento lexical, como mostram Martins (2013; 2019) e Duarte (2013) e da categoria objeto direto

Revista da Anpoll, Florianópolis, v. 52, n. esp., p. 173-197, jan.-dez., 2021 | 186 
anafórico e as mudanças em direção ao aumento da categoria nula para expressão dessa função no português brasileiro, como mostram os trabalhos de Freire e Vieira (2014), Freire e Duarte (2014), Freire (2012), Martins (2017) 9 .

Quanto à interface entre Sociolinguística e Funcionalismo, em termos de aplicação envolvendo reflexão e análise linguística, o Sociofuncionalismo: (i) oferece ferramentas para a exploração do jogo de relações entre formas e funções/significações: multifuncionalidade (uma forma e mais de uma função) e variação (mais de uma forma e uma função); (ii) permite estabelecer correlações entre formas variantes e contextos discursivos de realização; (iii) fornece explicações funcionais, considerando tanto a trajetória linguística quanto o contexto sócio-histórico, para fenômenos em mudança via gramaticalização (ex.: pronominalização de você a a gente; uso de aí e então como conectores; uso de olha, vê, sabe e entende como marcadores discursivos) e em variação (ex.: tu/você, nós/a gente; aí/então; olha/vê; sabelentende). Enfim, oferece condições para se lidar com a ideia de que os usos linguísticos desempenham papéis multifacetados; que a gramática abarca, ao lado de formas linguísticas regularizadas pela recorrência de uso, também formas emergentes e em processo de mudança rumo à regularização, as quais são sensíveis a pressões externas e internas da língua; que o ensino gramatical deve ser contextualizado (GÖRSKI; SIQUEIRA, 2017). Os artigos de Tavares e Görski (2003; 2006) ilustram em termos práticos algumas dessas contribuições.

\section{Considerações finais}

Neste artigo, exploramos dois tipos de articulação teórica a partir da TVM - em interfaces formal e funcional -, com base na da trajetória do GT de Sociolinguística da ANPOLL; consideramos algumas contribuições advindas para o ensino; e pontuamos, a seguir, alguns desafios postos nessas interfaces.

A respeito da Sociolinguística e gerativa, podemos dizer que as propostas e desafios dos estudos no GT são: (i) dar continuidade à discussão que se abre na associação da Teoria da Variação e Mudança linguística e o Gerativismo - pensando especificamente nos ganhos e redirecionamentos dos problemas empíricos de teorias para o estudo da

\footnotetext{
${ }^{9}$ Mesmo não assumindo a interface Sociolinguística e Teoria Gerativa, destacamos os trabalhos realizados por Silvia Vieira sobre ensino de gramática abordando fenômenos morfossintáticos no âmbito do GT.
}

Revista da Anpoll, Florianópolis, v. 52, n. esp., p. 173-197, jan.-dez., 2021 | 187 
mudança linguística que se constroem nessa interface; (ii) definir com mais propriedade questões teórico-metodológicas de novos modelos que surgem para a estudo de fenômenos de mudança (como o modelo de competição de gramáticas, por exemplo); (iii) dar continuidade à descrição e análise de fenômenos de mudança no português escrito no Brasil e à implementação do português brasileiro em textos de diferentes gêneros textuais/discursivos; e (iv) sistematizar resultados teóricos e empíricos e produzir material didático para o ensino de português.

$\mathrm{Na}$ interface sociofuncionalista, colocam-se como desafios: (i) investir na construção de variáveis independentes complexas, de modo a captar o caráter multidimensional e gradiente dos fenômenos linguísticos em variação e mudança; (ii) explorar - para além de fenômenos variáveis de natureza discursiva e de condicionadores funcionais e da convergência entre gramaticalização e variação no âmbito de um domínio funcional - o componente social da Sociolinguística, de modo a articular as diferentes camadas do significado social, incluindo aspectos estilísticos e identitários, com o componente funcional; (iii) continuar expandindo o olhar funcional - para gramática de construções, por exemplo -, articulado não somente à variação, mas também a diferentes tipos de condicionadores sociais; (iv) ampliar e sistematizar as contribuições de uma abordagem sociofuncionalista para o ensino.

\section{Agradecimentos}

MARM é bolsista Produtividade PQ-2 do Conselho Nacional de Desenvolvimento Científico e Tecnológico (CNPq - Brasil).

\section{Contribuição}

Edair Maria Görski: Conceptualização, Escrita - rascunho original; Marco Antonio Rocha Martins: Conceptualização, Escrita - rascunho original.

\section{Referências}

ABRAÇADO, J.; RONCARATI, C. (Orgs.) Português brasileiro: contato linguístico, heterogeneidade e história. Rio de Janeiro: 7Letras, 2003. 
ABRAÇADO, J.; RONCARATI, C. (Orgs.) Português brasileiro: contato linguístico, heterogeneidade e história II. Niterói/RJ: FAPERJ/EdUFF, 2008.

BERLINCK, R. A.; COELHO, I. L. A ordem do sujeito em construções declarativas na história do português brasileiro. In: CYRINO, S.; TORRES MORAIS, M. A. (Orgs.). Mudança sintática do português brasileiro: perspectiva gerativista. 1ed. São Paulo: Contexto, 2018, v. 4, p. 308-381.

BERLINCK, R. A.; COELHO, I. L.; CYRINO, S.; DUARTE, M. E. L.; MARTINS, M. Mudança sintática e a história do português brasileiro nos séculos XIX e XX. In: ARAÚJO SÁ JÚNIOR, L.; MARTINS, M. A. (Orgs.). Rumos da Linguística Brasileira no século XXI: historiografia, gramática e ensino. 1ed. São Paulo: Blucher, 2016, v. 1, p. 155-188.

BERLINCK, R. A.; BIAZOLLI, C. C.; BALSALOBRE, S. R. G. Gêneros do jornal e estilo: (re)visitando a variação linguística. In: GÖRSKI, E. M.; COELHO, I. L.; NUNES DE SOUZA, C. M. (Orgs.). Variação estilística: reflexões teóricometodológicas e propostas de análise. 1ed. Florianópolis: Insular, 2014, p. 261-279.

BERLINCK, R de A. A ordem V SN no português do Brasil: sincronia e diacronia. 1988. 265f. Dissertação (Mestrado em linguística) - Universidade Estadual de Campinas, Campinas, 1988.

BERLINCK. R. de A. A construção V SN no português do Brasil: uma visão diacrônica do fenômeno da ordem. In: TARALLO, F. (Org.). Fotografias sociolingüísticas. São Paulo: Pontes, 1989. p. 95-112.

BERLINCK, R. de A. La position du sujet en portugais: étude diachronique des variétés brésilienne et européene. 1995. Tese (Doutorado em Linguística) - Katholieke Universiteit Leuven, Belgium, 1995.

BERLINCK, R. de A. Brazilian Portuguese VS Order: a diachronic analysis. In: KATO, M.A.; NEGRÃO, E.V. (Eds.). Brazilian Portuguese and the null subject parameter. Madrid: Iberoamericana; Frankfurt: Vervuert, 2000. p. 175-194.

BRAGA, M. L. A concordância de número do sintagma nominal no Triângulo Mineiro. 1977. Dissertação (Mestrado em Língua Portuguesa) Rio de Janeiro: PUC, 1978.

BRAGANÇA, M. L. L. Uma proposta de articulação teórico-metodológica entre os campos variacionista, funcionalista e dialógico para o tratamento de variação/mudança: reflexões a partir da expressão do futuro do presente. 2017. $696 \mathrm{f}$. Tese (Doutorado) - Programa de Pós-graduação em Linguística, Universidade Federal de Santa Catarina, Florianópolis, 2017.

CAVALCANTE, S. R. O. Revisitando as construções com SE na história do Português Brasileiro. In: CYRINO, S.; TORRES DE MORAIS, M. A. (Orgs.). Mudança sintática 
do português: perspectiva gerativista. 1ed. São Paulo: Contexto, 2018, v. VI, p. 382419.

CAVAlCANTE, S. R. O. O uso de SE com infinitivo na história do Português: do Português Clássico ao Português Europeu e Brasileiro modernos. 2006. 227f. Tese (Doutorado em Linguística) - Instituto de Estudos da Linguagem, Universidade Estadual de Campinas, Campinas, 2006.

CAVALCANTE, S. R. O. Padrões estatísticos do encaixamento da mudança de SEpassivo a SE-indefinido na história do português. Alfa: Revista de Linguística (UNESP. São José do Rio Preto. Impresso), n. 55, v.2, p. 523-544, 2011.

CAVALCANTE, S.; DUARTE, M. E. L.; PAGOTTO, E. Clíticos no século XIX: uma questão de posição social? In: CALLOU, D.; BARBOSA, A. (Orgs.). A norma brasileira em construção: cartas a Rui Barbosa (1866 a 1899). Rio de Janeiro: Fundação Casa de Rui Barbosa, 2011, p. 167-218.

COELHO, I. L. A ordem V DP em construções monoargumentais: uma restrição sintático-semântica. 2000. 259f. Tese (Doutorado em Linguística) - Programa de Pósgraduação em Linguística, Universidade Federal de Santa Catarina, Florianópolis, 2000.

COELHO, I. L. Variação na sintaxe: estudo da ordem do sujeito no PB. In: RAMOS, J. (Org.). Estudos sociolinguísticos: quatro vértices do GT da ANPOLL. Belo Horizonte: Ed. da UFMG, 2006. p. 84-99.

CYRINO, S. O objeto nulo no português do Brasil: um estudo sintático-diacrônico. 1994. 227f. Tese (Doutorado em Linguística) - Universidade Estadual de Campinas, Campinas, 1994.

CYRINO, S. O objeto nulo no português do Brasil: um estudo sintático-diacrônico. Londrina: Ed. da UEL, 1997.

DÃO, S.F. GT de Sociolinguística. Revista da ANPOLL 1, p. 95-102, 1995.

DIAS, V. de C. A indeterminação do sujeito em textos baianos dos séculos XIX e XX: um estudo sociofuncionalista. 2017, 229f. Tese (Doutorado em Letras) - Instituto de Letras, Universidade Federal da Bahia, Salvador, 2017.

DILLINGER, M. Forma e função na linguística. In: D.E.L.T.A., v. 7, n. 1, p. 395-407, 1991.

DUARTE, M. E. L. Variação nas funções acusativa, dativa e reflexiva. In: MARTINS, M. A.; ABRAÇADO, J. (Orgs.). Mapeamento sociolinguístico do português brasileiro. 1ed. São Paulo: Contexto, 2015, p. 173-195.

DUARTE, M. E. L. O papel da linguística na evolução dos estudos gramaticais no Brasil. In: ARAÚJO SÁ JR, L.; MARTINS, M. A. (Orgs.). Rumos da Linguística 
Brasileira no Século XXI: historiografia, gramática e ensino. 1ed. São Paulo: Blucher Ed., 2016, p. 19-42.

DUARTE, M. E. L. Clítico acusativo, pronome lexical e categoria vazia no português do Brasil. In: TARALLO, F. (Org.) Fotografias sociolinguísticas. Campinas: Pontes, 1989, 19-34.

DUARTE, M. E. L. Variação e sintaxe: clítico acusativo, pronome lexical e categoria vazia no português do Brasil. 1986, 73f. Dissertação (Mestrado em Linguística), PUCSP, São Paulo, 1986.

DUARTE, M. E. L. A perda do princípio "Evite Pronome" no português brasileiro. 1995, 151f. Tese (Doutorado em Linguística) - Universidade Estadual de Campinas, Campinas, 1995.

DUARTE, M. E. L. O papel da sociolinguística na descrição da gramática da escrita contemporânea. In: MARTINS, M. A.; TAVARES, M. A. (Orgs.). Contribuições da Sociolinguística e da Linguística Histórica para o ensino de língua portuguesa. Natal: Ed. da UFRN, 2013b, p. 117-143.

DUARTE, M. E. L. (Org.). O sujeito em peças de teatro (1833-1992): estudos diacrônicos. São Paulo: Parábola editorial, 2012a.

DUARTE, M. E. L. Sobre o ensino da gramática nos níveis Fundamental e Médio: por que, quando e como? Revista Matraga, v. 19, n. 30, p. 41-60, 2012.

DUARTE, M. E. L. O papel da Sociolinguística no (re)conhecimento do português brasileiro Revista LETRAS, UFRJ, v. 1, p. 15-30, meio digital, 2013.

DUARTE, M. E. L. O sujeito nulo no português brasileiro. In: CYRINO, S; TORRESMORAIS, M. A. (Orgs.). Mudança sintática do português brasileiro: perspectiva gerativista. 1. ed. São Paulo: Contexto, 2018, v. 1, p. 26-71.

FREIRE, G. C; VIEIRA, S. R. Variação morfossintática e ensino de português. In: MARTINS, M. A.; TAVARES, M. A.; VIEIRA, S. R. (Orgs.). Ensino de Português e Sociolinguística. 1ed. São Paulo: Contexto, 2014, p. 07-169.

FREIRE, G. C; DUARTE, M. E. L. Como a escrita padrão recupera formas em extinção e implementa formas inovadoras. In: PAIVA, M. C.; GOMES, C. A. (Orgs.). Dinâmica da Variação e da Mudança na Fala e na Escrita. 1ed. Rio de Janeiro: Contra Capa, 2014, p. 9-168.

FREIRE, G. C. Clíticos acusativo e dativo no ensino de língua padrão. In: PAlOMANES, R.; BRAVIN, A. M. (Orgs.). Práticas de Ensino do Português. 1ed. São Paulo: Contexto, 2012, p. 91-109.

FREITAG, R. M. K. A expressão do passado imperfectivo no português: variação/gramaticalização e mudança. 2007, 238f. Tese (Doutorado em Linguística) - 
Programa de Pós-Graduação em Linguística, Universidade Federal de Santa Catarina, Florianópolis, 2007.

FREITAG, R. M. K. Dissecando a entrevista sociolinguística: estilo, sequência discursiva e tópico. In: GÖRSKI, E. M.; COELHO, I. L. NUNES DE SOUZA, C. M. (Orgs.). Variação estilística: reflexões teórico-metodológicas e propostas de análise. 1ed. Florianópolis: Insular, 2014, v. 1, p. 125-141.

GALVES, C.; KATO, M. A.; ROBERTS, I. (Orgs.). Português Brasileiro: uma segunda viagem diacrônica. 1 ed. Campinas: Editora da UNICAMP, 2019.

GÖRSKI, E.; TAVARES, M. A. O objeto de estudo na interface variação gramaticalização. In: BAGNO, M.; CASSEB-GALVÃO, V.; REZENDE, T. F. (Orgs.). Dinâmicas funcionais da mudança linguística. São Paulo: Parábola, 2017, p. 35-63.

GÖRSKI, E. M.; SIQUEIRA, M. A. Para além da questão: (não) ensinar gramática? Working Papers em Linguística - Gramática \& escola, v. 18, n. 2, p. 25-49, 2017.

GÖRSKI, E. M.; OLIVEIRA, L. C.; PIMPÃO, T. S. Do discurso para a gramática, da gramática para o discurso: uma entrevista com Sebastião Josué Votre. Working Papers em Linguística, v. 21, n. 1, p. 08-16, 2020.

KATO, M. A.; ROBERTS, I. (Orgs.). Português Brasileiro: uma viagem diacrônica. 2 ed. Campinas: Editora da UNICAMP, 1993.

KATO, M. A. Os frutos de um projeto herético: parâmetros na variação intralinguistica. In: DA HORA, D.; CHRISTIANO, E. (Orgs.) Estudos Lingüísticos: realidade brasileira. João Pessoa: Idéia, 1999. p. 95-106.

KROCH, A. Syntactic Change. In. BALTIN, M; COLLINS, C. (Eds.). The handbook of contemporary syntactic theory. Massachusetts. USA: Blackwell, 2001, p. 699-729.

KROCH, A. Reflexes of Grammar in Patterns of Language Change. Language Variation and Change, 1, p. 199-244, 1989.

LANGA-LACERDA, M.; GÖRSKI, E. Potencial analítico dos gêneros do discurso para os estudos variacionistas. Alfa: Revista de Linguística. [a sair]

LOPES, C. R. S. Retratos da variação entre "você" e "tu" no português do Brasil: sincronia e diacronia. In: RONCARATI, C.; ABRAÇADO, J. (Orgs.). Português Brasileiro II - contato lingüístico, heterogeneidade e história. 1ed. Niterói: EDUFF, 2008, p. 55-71.

MACEDO, A. T. de; RONCARATI, C.; MOLLICA, M. C. (Orgs.) Variação e discurso. Rio de Janeiro: Tempo Brasileiro, 1996.

MACHADO VIEIRA, M. dos S.; WIEDEMER, M. L. Sociolinguística variacionista e gramática de construções: os desafios e as perspectivas de compatibilização. In: 
MACHADO VIEIRA, M. dos S.; WIEDEMER, M. L. (Orgs.). Dimensões e experiências em Sociolinguística. São Paulo: Blucher, 2019, p. 85-120.

MARINS, J, E. O Parâmetro do Sujeito Nulo: uma analise contrastiva entre o português e o italiano. 2009, 126f. Dissertação (Mestrado em Letras (Letras Vernáculas)) - Universidade Federal do Rio de Janeiro, Rio de Janeiro, 2009.

MARINS, J, E. As repercussões da mudança na remarcação do sujeito nulo: um estudo diacrônico das sentenças existenciais no PB e no PE. 2013, 243f. Tese (Doutorado em Letras (Letras Vernáculas)) - Universidade Federal do Rio de Janeiro, Rio de Janeiro, 2013.

MARTINS, M. A. R; CAVALCANTE, S. R de O.; Coelho, I. L. Ordem do sujeito e colocação de clíticos na escrita brasileira dos séculos XIX e XX: reflexos da gramática do Português Brasileiro. Cadernos de Estudos Linguísticos, v. 62, p. 1-22, 2020.

MARTINS, M. A; VIEIRA, S. R.; TAVARES, M. A. Contribuições da Sociolinguística brasileira para o ensino de português. In: MARTINS, M. A; VIEIRA, S. R.;

TAVARES, M. A. (Orgs.). Ensino de Português e Sociolinguística. 1ed. São Paulo: Contexto, 2014, p. 7-35.

MARTINS, M. A.; COELHO, I. L.; CAVALCANTE, S. R. de O. Variação sintática e gerativismo. In: MARTINS, M. A.; ABRAÇADO, J. (Orgs.) Mapeamento sociolinguístico do português brasileiro. São Paulo: Contexto, 2015, p. 221-247.

MARTINS, M. A.; TAVARES, M. A. (Orgs.) Contribuições da Sociolinguística e da Linguística Histórica para o ensino de língua portuguesa. Natal, RN: EDUFRN, 2013.

MARTINS, M. A.; VIEIRA, S. R.; TAVARES, M. A. (Orgs.). Ensino de Português e Sociolinguística. São Paulo: Contexto, 2014.

MARTINS, M. A. Estruturas obsoletas no Português Brasileiro e o ensino de gramática na escola. In: PEREIRA, R. C. M.; PEDROSA, J. L. R.; FERRAZ, M. M. T. (Orgs.). Letramentos em cena: teorias e vivências. 1ed. João Pessoa: Ideia, 2019, p. 189-212. MARTINS, M. A._Em defesa do ensino de gramática. Revista do GELNE, v. 19, p. 103-117, 2017.

MARTINS, M. A. Competição de gramáticas do português na escrita catarinense dos séculos 19 e 20. 2009, 326f. Tese (Doutorado em Linguística) - Programa de PósGraduação em Linguística, Universidade Federal de Santa Catarina, Florianópolis, 2009.

MARTINS, M. A. A sintaxe dos pronomes pessoais clíticos na história do português brasileiro. In: CYRINO, S.; TORRES MORAIS, M. A. (Orgs.). Mudança sintática do português brasileiro: perspectiva gerativista. 1ed. São Paulo: Contexto, 2018, v. IV, p. 150-209. 
MASSARIOL, C. B.; YACOVENCO, L. C. A condição de distintividade na variação do sujeito pronominal de primeira pessoa do singular em cartas escritas por um capixaba. Revista (Con)Textos Linguísticos, Vitória, v. 14, n. 28, p. 473-491, 2020.

MENON, O. P. da S. O sistema pronominal do português. Revista Letras, Curitiba, n. 44, p. 91-106, 1995.

MOLLICA, M. C.; RONCARATI, C. Questões teórico-descritivas em sociolinguística aplicada e uma proposta de agenda. D.E.L.T.A., São Paulo, v. 17, n. especial, p. 45-55, 2001.

MOLLICA, M. C. M. Estudo da cópia nas construções relativas em português. 1977, f. Dissertação (Mestrado em Linguística) - Pontifícia Universidade Católica, Rio de Janeiro, 1977.

NARO, A. J.; VOTRE, S. J. Mecanismos funcionais do uso da língua: função e forma. D.E.L.T.A., São Paulo, v.8, n.2, p. 285-290, 1992.

NARO. A.; BRAGA, M. L. A interface sociolinguística/gramaticalização. Gragoatá, n. 9, p. 125-134, 2000.

NASCIMENTO, M. do. Teoria gramatical e mecanismos funcionais do uso da língua. In: D.E.L.T.A., São Paulo, v. 6, n. 1, p. 83-98, 1990.

OMENA, N. P. de. Pronome pessoal de terceira pessoa: suas formas variantes em função acusativa. 1978, 138f. Dissertação (Mestrado em Língua Portuguesa) Pontifícia Universidade Católica, Rio de Janeiro, 1978.

PAIVA, M. da C. A. de. Ordenação de cláusulas causais: forma e função. 1991, $238 f$. Tese (Doutorado em Linguística) - Faculdade de Letras, Universidade Federal do Rio de Janeiro, Rio de Janeiro, 1991.

PAREDES DA SILVA, V. L. Cartas cariocas: a variação do sujeito na escrita informal. 1988, 330f. Tese (Doutorado em Linguística) - Faculdade de Letras, Universidade Federal do Rio de Janeiro, Rio de Janeiro, 1988.

PIMPÃO, T. S. Uso variável do presente no modo subjuntivo: uma análise de amostras de fala e escrita das cidades de Florianópolis e Lages nos séculos XIX e XX. 2012, 303f. Tese (Doutorado em Linguística) - Programa de Pós-Graduação em Linguística da Universidade Federal de Santa Catarina, Florianópolis, 2012.

POPLACK, S. Grammaticalization and linguistic variation. In: NARROG, H.; HEINE, B. (Eds.). The Oxford handbook of grammaticalization. Oxford: Oxford University Press, 2011, p. 209-224.

RAMOS, J. M.; MENON, O. P. Variação e gramaticalização. In: MARTINS, M. A.; ABRAÇADO, J. (Orgs.) Mapeamento sociolinguístico do português brasileiro. São Paulo: Contexto, 2015, p. 271-285. 
ROCHA, W. J. C.; SOUSA, V. V. A alternância entre você e cê no sertão da ressaca: um estudo sob as lentes do sociofuncionalismo. Revista do GELNE, Natal/RN, v. 22, número 1, p. 203-214, 2020.

ROST SNICHELOTTO, C. A. "Olha" e "vê": caminhos que se entrecruzam. 2009, 408f. Tese (Doutorado em Linguística) - Programa de Pós-Graduação em Linguística, Universidade Federal de Santa Catarina, Florianópolis, 2009.

SAVEDRA, M. G. Estudos e pesquisas em sociolinguística no contexto plurilíngue do Brasil. Revista da ANPOLL. n. 29. p. 219-234, 2010.

SILVA, G. M. O e S.; MACEDO, Alzira. Análise sociolingüística de alguns marcadores conversacionais. In: MACEDO, A.; RONCARATI, C.; MOLLICA, M. C. (Orgs.).

Variação e discurso. Rio de Janeiro: Tempo Brasileiro, p. 11-49, 1989.

SOARES DA SILVA, H. O Parâmetro do sujeito nulo: confronto entre o português e o espanhol. 2006. 117f. Dissertação (Mestrado em Letras - Letras Vernáculas) Universidade Federal do Rio de Janeiro, Rio de Janeiro, 2006.

SOARES DA SILVA, H. Evidências da mudança em dados da Língua-E: o sujeito pronominal no português e no espanhol. 2011, 151f. Tese (Doutorado em Letras (Letras Vernáculas)) - Universidade Federal do Rio de Janeiro, 2011.

TARALLO, F.; KATO, M. A. Harmonia trans-sistêmica: variação inter e intralingüística. In: Preedição, Campinas, n. 5, p. 315-353, 1989.

TARALLO, F. Diagnosticando uma gramática brasileira: o português d'aquém-mar e d'além-mar ao final do século XIX. In: ROBERTS, I; KATO, M. (Orgs.). Português brasileiro: uma viagem diacrônica. Campinas, SP: Editora da UNICAMP, 1993, p.1242 .

TARALLO, F. Zelig: um camaleão lingüista. D.E.L.T.A., São Paulo, v. 2, n. 1, p. 127144, 1986.

TARALLO, F. Por uma Sociolinguística Românica "Paramétrica": Fonologia e Sintaxe. Ensaios de Linguística, UFMG, v. 13, p. 51-84, 1987.

TARALLO, F. Uma estória muito mal contada. D.E.L.T.A., São Paulo, v. 2, n. 4, p. 265-272, 1988.

TAVARES, M. A. Um estudo variacionista de AÍ, DAÍ, ENTÃo e E como conectores sequenciadores retroativo-propulsores na fala de Florianópolis. 1999. 175f. Dissertação (Mestrado em Linguística) - Programa de Pós-Graduação em Linguística, Universidade Federal de Santa Catarina, Florianópolis, 1999.

TAVARES, M. A. A gramaticalização de E, AÍ, DAÍ, e ENTÃo: estratificação/variação e mudança no domínio funcional da sequenciação retroativopropulsora de informações - um estudo sociofuncionalista. 2003, 286f. Tese (Doutorado 
em Linguística) - Programa de Pós-Graduação em Linguística, Universidade Federal de Santa Catarina, Florianópolis, 2003.

TAVARES, M. A.; GÖRSKI, E. M. Variação e sociofuncionalismo. In: MARTINS, M. A.; ABRAÇADO, J. (Org.). Mapeamento sociolinguístico do português brasileiro. São Paulo: Contexto, 2015. p. 249-270.

TAVARES, M. A.; GÖRSKI, E. M. Sociofuncionalismo: da teoria à prática pedagógica. In: SILVA, C. R.; HORA, D, da; CRISTIANO, M. E. (Orgs.) Lingüística e práticas pedagógicas. Santa Maria: Pallotti, 2006. p. 127-148.

TAVARES, M. A.; GÖRSKI, E. M. Experienciando a multiplicidade lingüística: o ensino de língua portuguesa sob um olhar sociofuncionalista. II Encontro Nacional de Ciências da Linguagem Aplicadas ao Ensino (II ECLAE), 2003, João Pessoa - PB. In: Anais [...], João Pessoa/PB: Idéia, 2004. Disponível em: http://www.leffa.pro.br/tela4/Textos/Textos/Anais/ECLAE_II/experienciando a multiplicidade/direita.htm

TESCH, L. M. A expressão do tempo futuro no uso capixaba: variação e gramaticalização. 2011. Tese. 190 f. (Doutorado em Linguística) - Faculdade de Letras, Universidade Federal do Rio de Janeiro, Rio de Janeiro, 2011.

TORRES CACOULLOS, Rena. Variation and grammaticalization. In: DÍAZCAMPOS, M. (Ed.). The handbook of Hispanic sociolinguistics. Oxford: WileyBlackwell, 2011, p. 148-167.

VALLE, C. R. M. Multifuncionalidade, mudança e variação de marcadores discursivos derivados de verbos cognitivos: forças semântico-pragmáticas, estilísticas e identitárias em competição. 2014, 415f. Tese (Doutorado em Linguística) - Programa de Pós-Graduação em Linguística da Universidade Federal de Santa Catarina, Florianópolis, 2014.

VANDRESEN, P. A trajetória do GT de Sociolinguística da ANPOLL - 1985-2001. In: RONCARATI, C.; ABRAÇADO, J. (Orgs.) Português Brasileiro: contato linguístico, heterogeneidade e história. Rio de Janeiro: 7Letras, 2003, p. 13-29.

VIEIRA, S. R. Variação estilística e ordem dos clíticos pronominais: a influência dos gêneros textuais e dos veículos jornalísticos. In: GÖRSKI, E. M.; COELHO, I. L.; NUNES DE SOUZA, C. M. (Orgs.). Variação estilística: reflexões teóricometodológicas e propostas de análise. 1ed. Florianópolis: Insular, 2014, 2014, p. 281301.

VOTRE, S. J.; NARO, A. J. Mecanismos funcionais do uso da língua. D.E.L.T.A., São Paulo, v.5, n.2, p. 169-184, 1989.

WEINREICH, U.; LABOV, W.; HERZOG, M. Fundamentos empíricos para uma teoria da mudança linguiística. Tradução Marcos Bagno. São Paulo: Parábola Editorial, 2006 [1968]. 
WIEDEMER, M. L.; MACHADO VIEIRA, M. dos S. Sociolinguística e gramática de construções: o envelope da variação. In.: FRANCESCHINI, L. T.; LOREGIANPENKAL, L. (Orgs.) Sociolinguística: estudos de variação, mudança e atitudes linguísticas, 2018, p. 41-77.

ZILLES, A.M. S. Grammaticalization of "a gente" as a cluster of changes: evidence from apparent and real time studies. Fórum Linguístico, Florianópolis, v. 4, n. 1, p. 13 46, 2007.

Recebido em: 10 de dezembro de 2020

Aceito em: 31 de maio de 2021

Publicado em agosto de 2021

Edair Maria Görski

E-mail: edagorski@ hotmail.com

ORCID: https://orcid.org/0000-0002-0797-1243

Marco Antonio Rocha Martins

E-mail: marcomartins.ufsc@gmail.com

ORCID: https://orcid.org/0000-0002-3999-3893 